\title{
Peritoneal Metastases in a Patient-derived Orthotopic Xenograft (PDOX) Model of Colon Cancer Imaged Non-invasively via Red Fluorescent Protein Labeled Stromal Cells
}

\author{
JUN HO PARK ${ }^{1,2,3}$, MING ZHAO ${ }^{1}$, HIROMICHI OSHIRO ${ }^{1,2}$, KENTARO MIYAKE $^{1,2}$, TAKASHI HIGUCHI ${ }^{1,2}$, \\ JOSE REYNOSO $^{1}$, SAHAR RAZMJOOEI ${ }^{1}$, MICHAEL BOUVET ${ }^{2}$, BRYAN CLARY ${ }^{2}$, ZHIYING ZHANG ${ }^{1,2}$, \\ NORIHIKO SUGISAWA ${ }^{1,2}$, JUN YAMAMOTO ${ }^{1,2}$, SHREE RAM SINGH ${ }^{4}$ and ROBERT M. HOFFMAN ${ }^{1,2}$ \\ ${ }^{1}$ AntiCancer Inc., San Diego, CA, U.S.A.; \\ ${ }^{2}$ Department of Surgery, University of California, San Diego, CA, U.S.A.; \\ ${ }^{3}$ Department of Surgery, Kangdong Sacred Heart Hospital, \\ Hallym University College of Medicine, Seoul, Republic of Korea; \\ ${ }^{4}$ Basic Research Laboratory, National Cancer Institute, Frederick, MD, U.S.A.
}

\begin{abstract}
Background/Aim: Patient-derived orthotopic xenograft (PDOX) models have patient-like clinical features and may be imaged, in case of some cancers, by passaging of the tumors through transgenic nude mice expressing redfluorescent protein (RFP) where they stably acquire RFP expressing stroma. The aim of the present study was to quantify red fluorescent area and intensity in colon-cancer peritoneal metastases in PDOX models in non-transgenic nude mice after passage in RFP transgenic nude mice by non-invasive external fluorescence imaging. Materials and Methods: Tumor fragments originating from a colon cancer patient with peritoneal metastases were implanted in transgenic RFP nude mice. Resultant tumors were harvested, and fragments were implanted in the same strain a second time. Passaged tumors stably acquired RFP-expressing stroma from their transgenic hosts. The tumor with RFPexpressing stromal cells were harvested and implanted orthotopically in non-transgenic nude mice. At eight weeks post-implantation, non-invasive external RFP images were obtained. RFP area and intensity were measured and correlated with tumor weight and volume. Results: Metastatic patient colon cancer can be stably and brightly labeled by passage in transgenic RFP-expressing nude mice
\end{abstract}

Correspondence to: Robert M. Hoffman, Anticancer, Inc., 7917 Ostrow St., San Diego, CA 92111, U.S.A. Tel: +1-858-654-2555, e-mail: all@anticancer.com; Shree Ram Singh, Basic Research Laboratory, National Cancer Institute, Frederick, MD 21702, U.S.A. Tel: +1 3018467331, e-mail: singhshr@mail.nih.gov

Key Words: Patient-derived orthotopic xenograft, colon cancer, peritoneal metastases, red-fluorescent protein, stromal cells, noninvasive imaging. such that tumor growth could be non-invasively imaged. Tumor growing could be non-invasively imaged when passaged to non-transgenic nude mice. A strong correlation between fluorescence intensity and area values with tumor weight and volume were established by external fluorescence imaging. Conclusion: This new tumor model of metastatic colon cancer can be used to evaluate novel therapeutics in real time for this recalcitrant disease.

Peritoneal metastasis is one of the major causes of death due to colon cancer relapse and is generally difficult to treat (1, 2 ). Approximately 5-10\% of patients with colon cancer develop peritoneal metastasis (2). Despite recent developments in diagnosis and therapy, the prognosis for this disease is poor $(2,3)$. Cytoreductive surgery together with hyperthermic intraperitoneal chemotherapy have shown promise for this disease (4-7). However, it was effective only in selected patients (3), which suggests that targeted therapy and non-invasive imaging methods are needed to detect and treat peritoneal metastasis of colon cancer. Peritoneal metastasis in colon cancer has been detected using various detection techniques including fluorescence (8-10). However, non-invasive imaging of peritoneal metastasis is still challenging.

Orthotopic xenografts of intact patient-derived tumor tissue in appropriate mouse strains can result in metastases to clinically relevant locations, unlike subcutaneous transplantation. We have established patient-derived orthotopic xenograft (PDOX) models in nude mice by surgical implantation for various cancers (11-14). PDOX models are much more patient-like than subcutaneous ectopic models (13) but make visualization of tumor growth and metastasis difficult. To address this problem, a method to introduce fluorescent-protein-expressing stroma into 
tumors has been developed by passaging patient tumor grafts through transgenic nude mice expressing a fluorescent protein (15). After passaging, these orthotopic xenografts with their acquired red-fluorescent protein (RFP) expressing stroma were orthotopically implanted into non-transgenic nude mice, enabling non-invasive imaging of tumor progression (15-18). Non-invasive methods present the obvious advantage of eliminating mortality and morbidity of mice, thus permitting serial imaging. Non-invasive imaging of cancer cells expressing fluorescent proteins could be helpful in real-time determination of efficacy of specific anticancer drugs.

In the present study, a strong correlation between measured fluorescence intensity and area, and weight and volume of metastatic tumors with RFP expressing stroma is shown.

\section{Materials and Methods}

Mice. 4-6 week old athymic nu/nu nude mice and transgenic RFP expressing athymic nu/nu mice were obtained from AntiCancer Inc. (San Diego, CA, USA). All surgical procedures and imaging were performed in accordance with an AntiCancer Institutional Animal Care and Use Committee (IACUC)-protocol specifically approved for this study, and in accordance with the principles and procedures outlined in the National Institute of Health Guide for the Care and Use of Animals under Assurance Number A3873-1. Mouse housing, feeding, surgical process, and imaging were conducted, and mice were humanely sacrificed as previously described (14).

Patient-derived tumor. The primary tumor was resected from a patient diagnosed with colon cancer. Peritoneal metastasis occurred a few months later, and the patient was treated with surgical resection and chemotherapy at the Division of Surgical Oncology, University of California, San Diego, USA (UCSD). A fresh sample of metastatic colon cancer was obtained immediately after patient surgery with informed patient consent and IRB approval. The tumor was cut into fragments and initially implanted subcutaneously in nude mice. We have previously reported the establishment of an orthotopic model of patient derived metastatic colon cancer with the method of surgical orthotopic implantation (SOI) used in the present study (11).

Establishment of PDOX model of colon cancer with RFP expressing peritoneal metastases. Patient colon cancer peritoneal metastases growing in nude mice were harvested, cut into $5 \mathrm{~mm}$ fragments, and implanted subcutaneously in transgenic RFP-expressing nude mice. After two passages, tumors stably containing RFP-expressing stromal cells were obtained and cut into fragments (Figure 1A). After non-transgenic nude mice were anesthetized with ketamine, 1-2 cm skin incisions were made at the midline of the abdomen. Surgical sutures (8-0 nylon) were used to implant tumor fragments onto the peritoneum. Wounds were closed using 6-0 nylon sutures.

Fluorescence imaging of peritoneal tumors and measurement of tumor weight and volume. Eight weeks after RFP-expressing tumors were implanted, mice were anesthetized for non-invasive external red fluorescence imaging. Fluorescence intensity and area were measured and calculated using the UVP ibox ${ }^{\circledR}$ (Analytik Jena, Jena, Germany). Mice were then sacrificed for direct measurements of tumor weight and volume. Frozen tissue sections were observed for fluorescence with an FV1000 confocal laser microscope (Olympus co). Excitation wavelength for RFP fluorescence was $559 \mathrm{~nm}$. Tissues were viewed under $4 \times$ and $20 \times$ objective lenses.

Statistical analysis. SPSS statistics 22.0 (SPSS Inc.) was used for statistical analyses. Pearson correlation coefficient and linear regression were used to assess the various possible relationships among different variables. A $p$-value of $\leq 0.05$ was considered statistically significant for all comparisons.

\section{Results and Discussion}

Orthotopically implanted tumors grew in the peritoneum of non-transgenic nude mice. These tumors had sufficient RFP to permit non-invasive imaging through the abdominal wall (Figure 1B-D). FV1000 confocal laser microscopy showed persistence of RFP-expressing tumor stroma acquired from passaging through RFP-expressing nude mice prior to implantation into non-transgenic nude mice (Figure 1E, F).

Tumor fluorescence area and intensity were quantitated weekly from week 2 to week 6 post implantation (Figure 1G). RFP area and intensity strongly correlated with tumor weight and volume measured upon autopsy (Figure 2). The strongest correlation was between fluorescence area and tumor weight $(\mathrm{r}=0.869, p<0.001$, Figure $2 \mathrm{~A})$. Fluorescence area correlated with tumor volume $(\mathrm{r}=0.771$, Figure $2 \mathrm{~B})$. Fluorescence intensity correlated with tumor weight $(\mathrm{r}=0.867$, Figure 2C) and tumor volume ( $\mathrm{r}=0.815$, Figure 2D). All correlations were statistically significant.

Implantation of human tumors into nude mice changed the paradigm in preclinical cancer research (19). Orthotopic implantation of tumors in nude mice enabled patient-like models to be established to investigate individualized patient therapies $(12,14)$. One shortcoming of this approach was that the orthotopic tumors had no fluorescence. Previously, we have developed imageable PDOX models for various cancers growing the tumor in transgenic RFP expressing nude mice $(15-17,20)$. This is the first report of non-invasive external fluorescent imaging of orthotopically-xenografted peritoneal tumors derived from a colon-cancer patient's peritoneal metastasis that had been passaged through RFPexpressing transgenic nude mice.

The present report demonstrates a strong correlation between fluorescence intensity and area by non-invasive fluorescent imaging of PDOX tumors with RFP-expressing stroma from double passage through RFP-expressing transgenic nude mice, and their weight and volume measured upon autopsy. We had previously made such correlation with RFP-labeled stroma in a pancreatic cancer PDOX (21) and also with labeled cancer cells growing orthotopically (22). The present report is the first observation of correlation between tumor stromal cell fluorescence and tumor volume and weight in a colon cancer PDOX. 

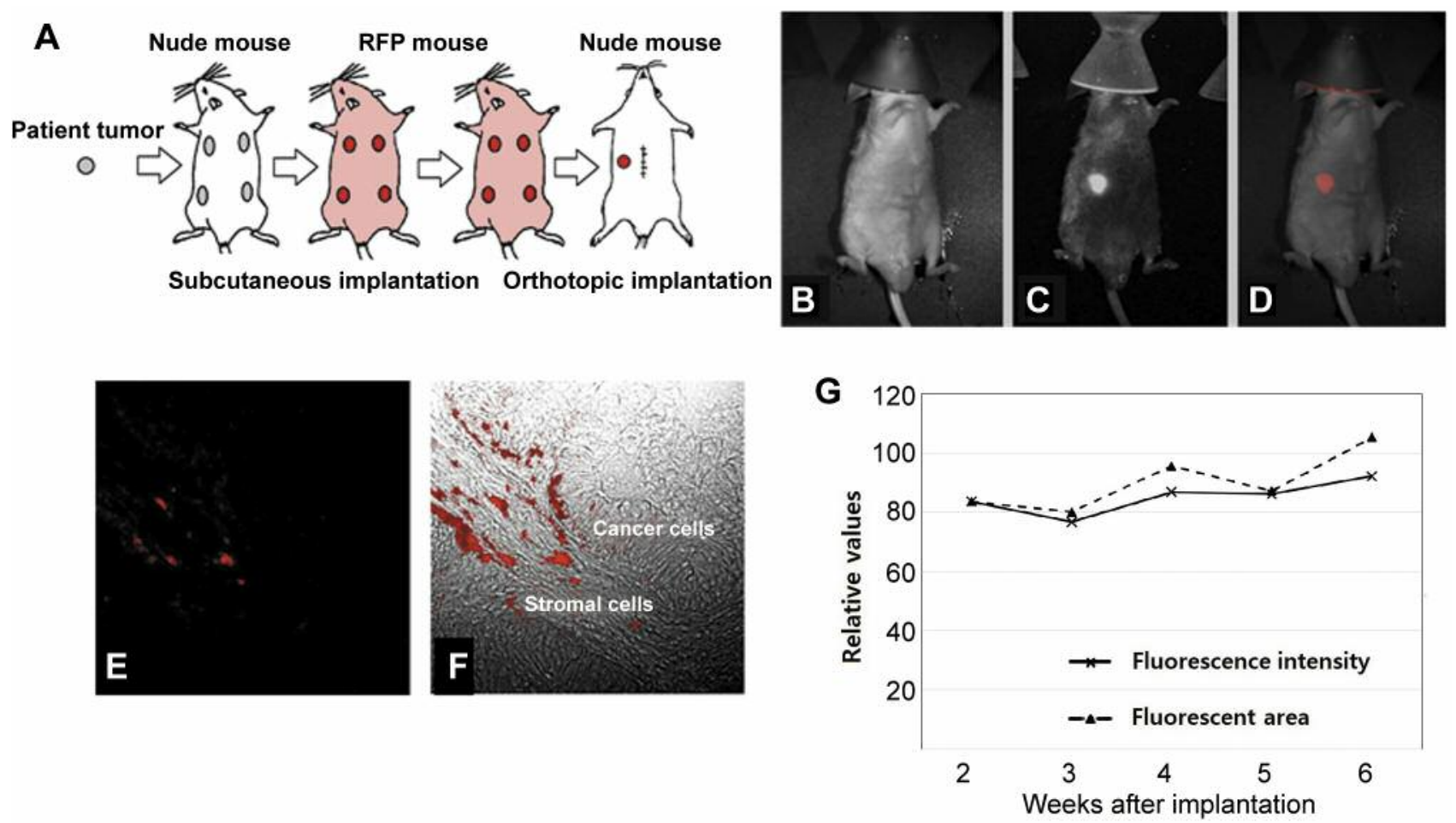

Figure 1. Development of non-invasive imageable orthotopic xenografts of peritoneal metastatic human colon cancer. (A) Experimental schema used to develop imageable orthotopic xenografts of peritoneal metastatic human colon cancer with RFP-expressing stroma (UVP iBOX imaging). (B-D) Non-invasive images of a colon cancer peritoneal metastatic tumor. (B) Bright field image. (C) Red fluorescence image. (D) Merged image. $F V 1000^{\circledR}$ confocal laser microscopy images from frozen sections of the colon cancer peritoneal metastatic PDOX tumor with RFP expressing stroma. (E) Red fluorescence image. $(F)$ Merged image. $(G)$ Tumor fluorescence area and intensity. Average fluorescence intensity and area values obtained weekly from week 2 to week 6 post-implantation.

Therefore, serially acquired fluorescence intensity and area values can be used to assess the antitumor effects of different therapeutics over time in PDOX models. This model will allow approved and experimental drugs to be rapidly screened to evaluate efficacy for individual patients, which should help to tailor patient therapies. This model will also improve our ability to discover novel effective agents for treating metastatic colon cancer and other cancer types.

\section{Conflicts of Interest}

JHP, HO, KM, TH, SR, ZZ, NS, JY and RMH are or were unsalaried associates of AntiCancer. MZ and JR are employees of AntiCancer. AntiCancer uses PDOX models for contract research. The Authors declare that there are no potential conflicts of interest.

\section{Authors' Contributions}

JHP and RMH were involved in study conception and design. JHP, MZ, HO, KM, TH, JR, SR, ZZ, NS and JM were involved in data acquisition. JHP, MZ, HO, KM, TH, JR, SR, MB, BC, ZZ, NS, JM, SRS and RMH analyzed and interpreted data. JHP and RMH prepared the manuscript. SRS provided critical revision of the manuscript. All Authors reviewed the manuscript.

\section{Acknowledgements}

This paper is dedicated to the memory of A.R. Moossa, M.D. and Sun Lee, M.D.

\section{References}

1 Nadler A, McCart JA and Govindarajan A: Peritoneal carcinomatosis from colon cancer: a systematic review of the data for cytoreduction and intraperitoneal chemotherapy. Clin Colon Rectal Surg 28(4): 234-246, 2015. PMID: 26648794. DOI: $10.1055 / \mathrm{s}-0035-1564431$

2 Nagata H, Ishihara S, Hata K, Murono K, Kaneko M, Yasuda K, Otani K, Nishikawa T, Tanaka T, Kiyomatsu T, Kawai K, Nozawa $\mathrm{H}$ and Watanabe T: Survival and prognostic factors for metachronous peritoneal metastasis in patients with colon cancer. Ann Surg Oncol 24(5): 1269-1280, 2017. PMID: 27995451. DOI: $10.1245 / \mathrm{s} 10434-016-5732-\mathrm{z}$

3 Lemmens VE, Klaver YL, Verwaal VJ, Rutten HJ, Coebergh JW and de Hingh IH: Predictors and survival of synchronous peritoneal carcinomatosis of colorectal origin: a populationbased study. Int J Cancer 128: 2717-2725, 2011. PMID: 20715167. DOI: $10.1002 /$ ijc. 25596

4 Sugarbaker PH, Zhu BW, Sese GB and Shmookler B: Peritoneal carcinomatosis from appendiceal cancer: results in 69 patients 
A

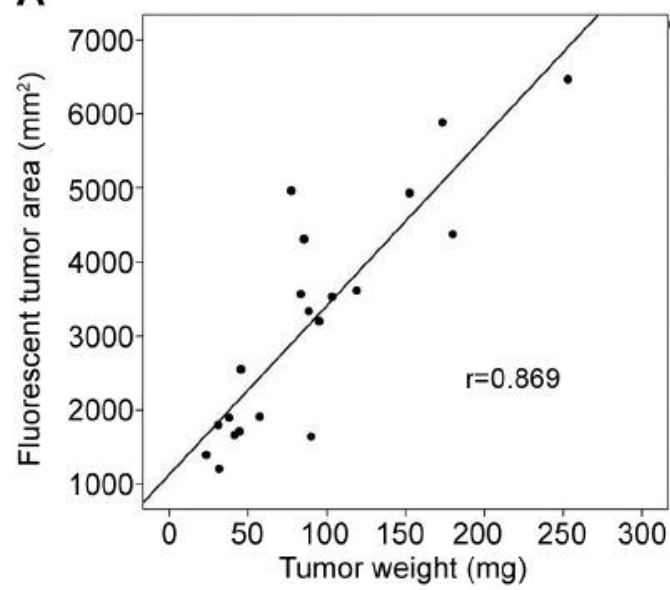

C

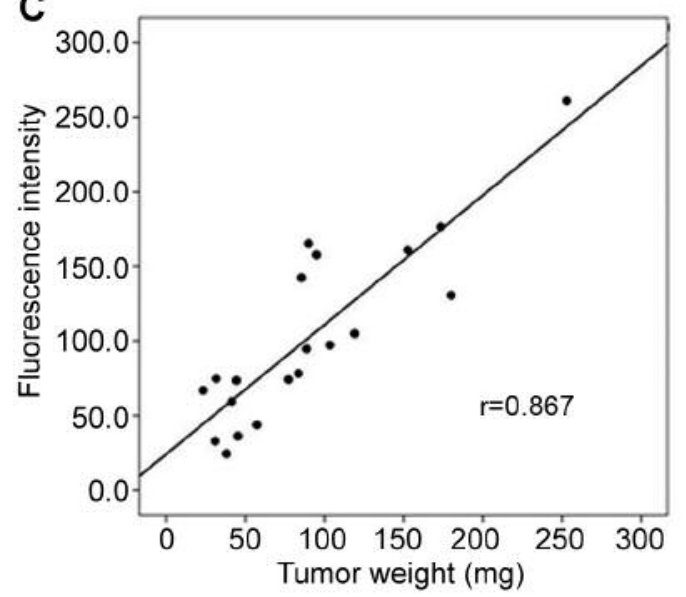

B

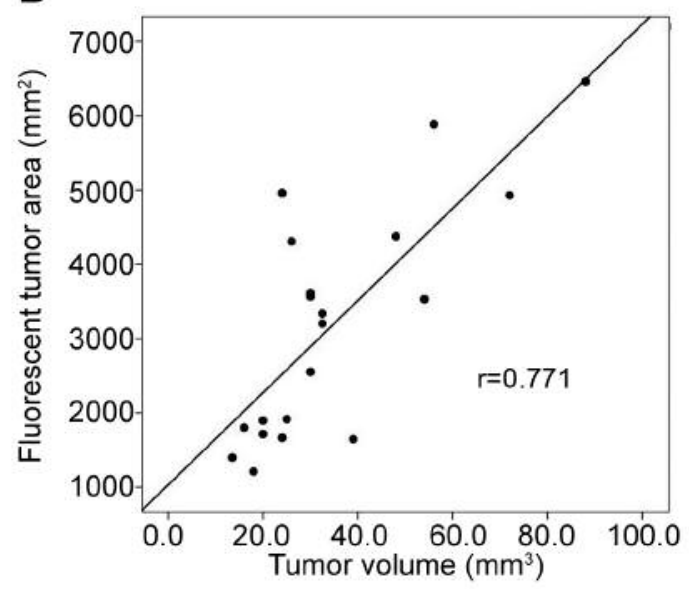

D

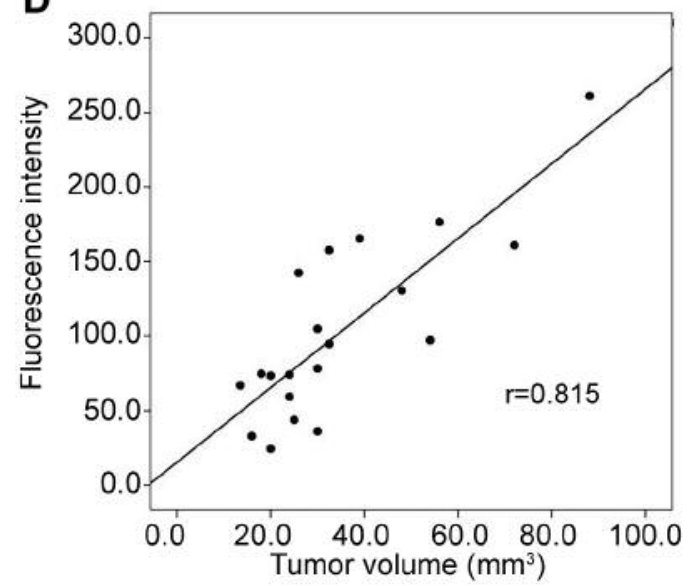

Figure 2. Correction between RFP area and intensity with tumor weight and volume. Correlation of tumor fluorescent area $(A, B)$ and fluorescence intensity $(C, D)$ with tumor weight and volume.

treated by cytoreductive surgery and intraperitoneal chemotherapy. Dis Colon Rectum 36(4): 323-329, 1993. PMID: 8458256. DOI: 10.1007/BF02053933

5 Verwaal VJ, van Ruth S, de Bree E, van Sloothen GW, van Tinteren H, Boot H and Zoetmulder FA: Randomized trial of cytoreduction and hyperthermic intraperitoneal chemotherapy versus systemic chemotherapy and palliative surgery in patients with peritoneal carcinomatosis of colorectal cancer. J Clin Oncol 21: 3737-3743, 2003. PMID: 14551293. DOI: 10.1200/ JCO.2003.04.187

6 Glehen O, Kwiatkowski F, Sugarbaker PH, Elias D, Levine EA, De Simone M, Barone R, Yonemura Y, Cavaliere F, Quenet F, Gutman M, Tentes AA, Lorimier G, Bernard JL, Bereder JM, Porcheron J, Gomez-Portilla A, Shen P, Deraco M and Rat P: Cytoreductive surgery combined with perioperative intraperitoneal chemotherapy for the management of peritoneal carcinomatosis from colorectal cancer: a multi-institutional study. J Clin Oncol 22: 3284-3292, 2004. PMID: 15310771. DOI: 10.1200/ JCO.2004.10.012
7 Aoyagi T, Terracina KP, Raza A and Takabe K: Current treatment options for colon cancer peritoneal carcinomatosis. World J Gastroenterol 20(35): 12493-12500, 2014.

8 Tanaka T, Kawai Y, Kanai M, Taki Y, Nakamoto Y and Takabayashi A: Usefulness of FDG-positron emission tomography in diagnosing peritoneal recurrence of colorectal cancer. Am J Surg 184(5): 433-436, 2002. PMID: 12433608. DOI: $10.1016 / \mathrm{S} 0002-9610(02) 01004-8$

9 Hutteman M, Mieog JS, van der Vorst JR, Dijkstra J, Kuppen PJ, van der Laan AM, Tanke HJ, Kaijzel EL, Que I, van de Velde CJ, Löwik CW and Vahrmeijer AL: Intraoperative near-infrared fluorescence imaging of colorectal metastases targeting integrin $\alpha(v) \beta(3)$ expression in a syngeneic rat model. Eur J Surg Oncol 37(3): 252-257, 2011. PMID: 21215590. DOI: 10.1016/ j.ejso.2010.12.014

10 Kondo Y, Murayama Y, Konishi H, Morimura R, Komatsu S, Shiozaki A, Kuriu Y, Ikoma H, Kubota T, Nakanishi M, Ichikawa D, Fujiwara H, Okamoto K, Sakakura C, Takahashi K, Inoue K, Nakajima $\mathrm{M}$ and Otsuji E: Fluorescent detection of 
peritoneal metastasis in human colorectal cancer using 5aminolevulinic acid. Int J Oncol 45(1): 41-46, 2014. PMID: 24821500. DOI: 10.3892/ijo.2014.2417

11 Fu XY, Besterman JM, Monosov A and Hoffman RM: Models of human metastatic colon cancer in nude mice orthotopically constructed by using histologically intact patient specimens. Proc Natl Acad Sci USA 88: 9345-9349, 1991. PMID: 1924398. DOI: $10.1073 /$ pnas.88.20.9345

12 Kawaguchi K, Miyake K, Han Q, Li S, Tan Y, Igarashi K, Kiyuna T, Miyake M, Higuchi T, Oshiro H, Zhang Z, Razmjooei S, Wangsiricharoen S, Bouvet M, Singh SR, Unno M and Hoffman $\mathrm{RM}$ : Oral recombinant methioninase (o-rMETase) is superior to injectable rMETase and overcomes acquired gemcitabine resistance in pancreatic cancer. Cancer Lett 432: 251-259, 2018 PMID: 29928962. DOI: 10.1016/j.canlet.2018.06.016

13 Hoffman RM: Patient-derived orthotopic xenografts: better mimic of metastasis than subcutaneous xenografts. Nature Rev Can 15: 451-452, 2015. PMID: 26422835. DOI: $10.1038 / \mathrm{nrc} 3972$

14 Miyake K, Kiyuna T, Miyake M, Kawaguchi K, Zhang Z, Wangsiricharoen S, Razmjooei S, Oshiro H, Higuchi T, Li Y, Nelson SD, Murakami T, Hiroshima Y, Kumamoto T, Matsuyama R, Bouvet M, Singh SR, Chawla SP, Endo I and Hoffman RM: Gemcitabine combined with docetaxel precisely regressed a recurrent leiomyosarcoma peritoneal metastasis in a patient-derived orthotopic xenograft (PDOX) model. Biochem Biophys Res Commun 509(4): 1041-1046, 2019. PMID: 30660363. DOI: 10.1016/j.bbrc.2019.01.046

15 Suetsugu A, Katz M, Fleming J, Truty M, Thomas R, Saji S, Moriwaki H, Bouvet $M$ and Hoffman RM: Non-invasive fluorescent-protein imaging of orthotopic pancreatic-cancerpatient tumorgraft progression in nude mice. Anticancer Res 32: 3063-3067, 2012. PMID: 22843874.

16 Kiyuna T, Murakami T, Tome Y, Kawaguchi K, Igarashi K, Miyake K, Kanaya F, Singh A, Eilber FC and Hoffman RM: Analysis of stroma labeling during multiple passage of a sarcoma imageable patient-derived orthotopic xenograft (iPDOX) in red fluorescent protein transgenic nude mice. J Cell Biochem 118: 3367-3371, 2017. PMID: 28300287. DOI: $10.1002 /$ jcb. 25991

17 Kiyuna T, Murakami T, Tome Y, Igarashi K, Kawaguchi K, Russell T, Eckardt MA, Crompton J, Singh A, Bernthal N, Bukata S, Federman N, Kanaya F, Eilber FC and Hoffman RM: Labeling the stroma of a patient-derived orthotopic xenograft (PDOX) mouse model of undifferentiated pleomorphic softtissue sarcoma with red fluorescent protein for rapid noninvasive imaging for drug screening. J Cell Biochem 118: 361365, 2017. PMID: 27357060. DOI: 10.1002/jcb.25643
18 Kawaguchi K, Igarashi K, Li S, Han Q, Tan Y, Kiyuna T, Miyake K, Murakami T, Chmielowski B, Nelson SD, Russell TA, Dry SM, Li Y, Unno M, Eilber FC and Hoffman RM: Combination treatment with recombinant methioninase enables temozolomide to arrest a BRAF V600E melanoma in a patientderived orthotopic xenograft (PDOX) mouse model. Oncotarget 8: 85516-85525, 2017. PMID: 29156737. DOI: 10.18632/ oncotarget.20231

19 Hoffman RM: Patient-derived mouse models of cancer. New York, Humana Press, Springer Nature, 2017.

20 Oshiro H, Kiyuna T, Tome Y, Miyake K, Kawaguchi K, Higuchi T, Miyake M, Zhang Z, Razmjooei S, Barangi M, Wangsiricharoen S, Nelson SD, Li Y, Bouvet M, Singh SR, Kanaya F and Hoffman RM: Detection of metastasis in a patient-derived orthotopic xenograft (PDOX) model of undifferentiated pleomorphic sarcoma with red fluorescent protein. Anticancer Res 39: 81-85, 2019. PMID: 30591443. DOI: 10.21873/anticanres.13082

21 Hiroshima Y, Zhao M, Maawy A, Zhang Y, Katz MH, Fleming JB, Uehara F, Miwa S, Yano S, Momiyama M, Suetsugu A, Chishima T, Tanaka K, Bouvet M, Endo I and Hoffman RM: Efficacy of Salmonella typhimurium A1-R versus chemotherapy on a pancreatic cancer patient-derived orthotopic xenograft (PDOX). J Cell Biochem 115: 1254-1261, 2014. DOI: $10.1002 /$ jcb. 24769

22 Katz MH, Takimoto S, Spivack D, Moossa AR, Hoffman RM and Bouvet $\mathrm{M}$ : A novel red fluorescent protein orthotopic pancreatic cancer model for the preclinical evaluation of chemotherapeutics. J Surg Res 113: 151-160, 2003. PMID: 12943825. DOI: 10.1016/S0022-4804(03)00234-8
Received March 12, 2019

Revised April 8, 2019

Accepted April 9, 2019 